\title{
El nuevo Código de Procedimiento Administrativo y de Procedimiento Contencioso Administrativo y la constitucionalización del derecho administrativo en Colombia*
}

\section{The New Code of Administrative Procedure and Administrative Procedure Law and Administrative Law Constitutionalisation Colombia}

\author{
Corina Dugue Ayala \\ Aura Catalina Martínez Cruz
}

\section{Resumen}

El artículo presenta el contexto social y político en que se desarrolla la actual reforma al Código de Procedimiento Administrativo y de lo Contencioso Administrativo; así mismo, explica sus grandes cambios en aras de contribuir a la concreción de un Estado social y a la globalización del derecho administrativo. De otra parte, analiza algunos vacíos que no alcanzó a llenar la reforma.

Palabras clave: Procedimiento administrativo, procedimiento contencioso administrativo, principios, función pública, medios de control judicial

\begin{abstract}
This academic article presents the social and political context in which the reform to the code of administrative procedure and administrative litigation is developed; it also explains the large changes in the code, for the purpose of contributing to the construction of a social State and the globalization of administrative law. On the other hand, this article analyzes certain voids that reform did not overcome such as the regulations that ensure systematic funding of the judicial power, or an efficient management of human talent.
\end{abstract}

Keywords: Administrative procedures, administrative law, principles, civil office, means of judicial control

* Artículo de reflexión.

** Tutoras de la Maestría de Derecho Público de la Facultad de Derecho, Universidad Santo Tomás de Bogotá. 


\section{INTRODUCCIÓN}

Mediante la Ley 1437 de 2011, el Congreso de CoIombia expidió el nuevo Código de Procedimiento Administrativo y de lo Contencioso Administrativo. Este nuevo texto normativo es el resultado de un esfuerzo mancomunado de las tres ramas del poder público, bajo el liderazgo del Consejo de Estado. Este, en el año 2007, creó una comisión redactora, la cual, a su vez, auspició una participación amplia de todos los servidores judiciales de la jurisdicción, de los representantes de los demás poderes públicos, incluidos los órganos de control, y de los académicos y estudiosos de esta área del derecho, todos los cuales debatieron las iniciativas presentadas en las mesas de trabajo y en los paneles realizados a lo largo y ancho del país y, en especial, en los encuentros anuales de la jurisdicción contenciosa administrativa. Dicho texto legal, que entrará en vigencia el próximo 2 de julio de 2012, se constituye en el primer cimiento para la gran reforma a la justicia que tanto anhela el país.

La nueva normatividad intenta, a grandes rasgos, concretar, en líneas generales, la constitucionalización de la función pública con la consecuente realización de los derechos fundamentales en sede administrativa. Así mismo, garantizar la seguridad jurídica a través de la aplicación unificada de la jurisprudencia del Consejo de Estado, tanto en sede administrativa como judicial. El nuevo estatuto se expide en una coyuntura particularmente compleja para la vida del país, caracterizada por un déficit de confianza entre las instituciones y el ciudadano, con una rama judicial deslegitimada por la congestión y la demora de sus fallos. Por esta razón, entre los objetivos que fija el código se encuentran la agilización de los procedimientos administrativos y judiciales, la simplificación de los trámites, la garantía del debido proceso, la práctica de pruebas con eficiencia y eficacia, la implementación de la oralidad y la adecuación de los procedimientos a las nuevas tecnologías informáticas.
Con el fin de divulgar el nuevo código e iniciar la pedagogía ciudadana, el Consejo de Estado organizó, los días 1, 2 y 3 de febrero de 2010, un seminario internacional con la participación de los miembros de la comisión redactora, los representantes de los organismos de control y dos profesores universitarios comparatistas provenientes de España y de Venezuela. En este artículo académico se sintetizan algunas de las ideas de los intervinientes en el seminario, a la luz de los desarrollos conceptuales de la doctrina del derecho administrativo provenientes de diferentes latitudes. Inicia con una introducción contentiva del contexto social y político dentro del cual se llevó a cabo la reforma. Luego,en dos apartados se trata, primero, los principales cambios tanto en el procedimiento administrativo como en el de lo contencioso administrativo. En una segunda parte se formulan algunos cuestionamientos a la reforma, identificando los problemas que no alcanzó a resolver y los vacíos en algunos temas cruciales para la implementación de la reforma. Finalmente, se proponen unas conclusiones $y$ recomendaciones.

\section{EL CONTEXTO SOCIAL Y POLÍTICO DE LA REFORMA}

Un primer diagnóstico acerca del funcionamiento del Estado colombiano muestra que este es ineficiente en la marcha ordinaria de los asuntos que le competen. En general, el Estado colombiano cuenta con una administración pública anacrónica, hipertrofiada y tendencialmente inclinada a la comisión de actos abusivos en contra de los ciudadanos. De otro lado, aquella también se encuentra prisionera de un inadecuado entendimiento del principio de legalidad y de una estricta sujeción a los procedimientos, los que en muchos casos conducen a la negación del derecho material o sustancial por su predisposición a privilegiar lo formal. 
En sede judicial, y en particular con respecto a la jurisdicción contenciosa administrativa, la realidad tampoco es muy alentadora. En esta se puede observar cierta inseguridad jurídica producto del fenómeno de la "federalización de la jurisprudencia", consistente en que cada tribunal de departamento genera sus líneas jurisprudenciales, las cuales, en algunos casos, resultan contradictoras entre sí o con las del Consejo de Estado. A nivel de este cuerpo tampoco existe mucho rigor en la construcción de las líneas jurisprudenciales, lo que conduce a que el juez administrativo "se sienta perdido"en el momento de citar un precedente judicial, debido a que sobre un mismo tema pueden llegar a existir pronunciamientos contradictorios en un periodo muy corto, incluso provenientes de una misma sala.

A los problemas que de tiempo atrás afectan a la administración, se suman otros nuevos, propios de la etapa que hoy viven las sociedades contemporáneas, en virtud del llamado fenómeno de la globalización que viene estableciendo nuevos paradigmas o modificando los hasta ahora existentes. Desafortunadamente, en Colombia los administradores públicos, en su gran mayoría, no han captado las repercusiones de la globalización del derecho y, por ende, aún no incorporan los nuevos paradigmas en su quehacer diario. Por ejemplo, se resisten a utilizar las nuevas tecnologías para avanzar hacia procedimientos virtuales o a realizar rendiciones de cuentas en forma mediática, lo que permitiría mejorar la comunicación con los gobernados, aferrados tercamente a las formalidades del Estado de derecho.

Al respecto, Barri Bozeman (1998) indica que todas las organizaciones en el contexto de la actual globalización son públicas. El autor explica que, por lo general, las organizaciones públicas y las privadas se perciben como si fueran esencialmente distintas. Sin embargo, las privadas, a menudo, tienen rasgos propios de las públicas: pueden estar reguladas por entes estatales o recibir fondos del gobierno y, por tanto, estar sujetas al escrutinio de aquel. Al mismo tiempo, las organizaciones gubernamentales, así como las privadas, se regulan cada vez más por las fuerzas del mercado y trabajan de manera activa en la búsqueda de beneficios.

En el mismo sentido, Samuel Yong Serrano (2009: 116), en su texto sobre la responsabilidad pública y privada, explica cómo cada vez es más tenue la línea divisoria entre los regímenes de aplicación de la responsabilidad pública y la privada, y cómo el deber de no causar daño a otro y la obligación de indemnizar los daños causados es una las máximas que gobiernan la convivencia actual, razón por la cual hoy avanzamos hacia un Estado que se hace cada vez más responsable, obligándose a indemnizar a las personas que se encuentran en su territorio cuando se les cause un perjuicio o daño, que las mismas no tuvieren el deber de soportar. Aunque en todos los casos se deba establecer el daño, el nexo causal y la antijuridicidad de la acción para exigir más la reparación, ya sea en el área contractual o extracontractual, poco a poco se avanza hacia una teoría objetiva de la responsabilidad del Estado, que permita en todos los casos la realización efectiva de los derechos fundamentales.

Otro de los nuevos paradigmas que han debido enfrentar, desde la Constitución de 1991, la Administración Pública en general y la jurisdicción contenciosa administrativa en particular $-y$ que no parece haberlo hecho por lo menos en forma completa- es el de la constitucionalización del derecho.

En Colombia no parece haberse asumido la idea de que el derecho administrativo y la jurisdicción que lo materializa a los casos concretos es el derecho constitucional concretizado. El reflejo de esta situación, que mantiene un divorcio entre los dos sistemas normativos, lo constituyen sin duda los frecuentes enfrentamientos y las decisiones contrapuestas entre el Consejo de Estado y la Corte 
Constitucional, con la dificultad adicional -que afecta de manera grave el principio de la seguridad jurídica- de que las decisiones del primero, por versar sobre asuntos concretos, acaban por primar sobre las interpretaciones y determinaciones abstractas de la segunda.

A los problemas estructurales de vieja data (congestión, retardo, exceso de formalismo, etc.) y a los que podíamos Ilamar ideológicos (ausencia de percepción sobre el impacto de la globalización en el derecho y la administración pública, mantenimiento del divorcio entre derecho constitucional y derecho administrativo) habría que agregar los desafíos que enfrenta la jurisdicción contenciosa administrativa, en términos de aumento de la demanda de justicia y carencia de medios administrativos y presupuestales para su adecuado funcionamiento, que se reflejan en los siguientes datos, ofrecidos por el doctor Hernando Torres Corredor, magistrado de la Sala Administrativa del Consejo Superior de la Judicatura.

No obstante que esta jurisdicción tan solo atiende el $9 \%$ del total de la demanda de justicia en el país -el 89\% corresponde a la justicia ordinaria (penal, civil y laboral)-, desde el 2005 dicha demanda se ha incrementado en un $237 \%$, resultando por tanto insuficientes las medidas de descongestión, en las cuales se pasó de una inversión de 1.600 millones en el 2006 a 30.000 millones en el 2010.

\section{LOS PRINCIPALES CAMBIOS EN EL PROCEDIMIENTO ADMINISTRATIVO $Y$ EN LO CONTENCIOSO ADMINISTRATIVO}

La actual reforma concibió importantes cambios en el procedimiento administrativo, los cuales buscan principalmente la realización efectiva de los derechos y el respeto al debido proceso.

Los cambios más relevantes se observan en la inclusión de nuevos principios, el mayor alcance al derecho de petición, la organización del procedimiento administrativo general y sancionatorio, y la aplicación o extensión de la jurisprudencia unificada en sede administrativa.

\section{a. La inclusión de nuevos principios acordes con los objetivos de la reforma}

Los objetivos de la reforma, analizados a la luz de la C.P. de 1991, aparecen como un avance hacia el constitucionalismo en Colombia. En los objetivos 1, 2 y 3 del Código se habla de eficacia de derechos y de la labor pedagógica de la administración para con los ciudadanos, en cuanto a sus derechos $y$ deberes. Los objetivos 4, 5, 6 y 7 establecen las garantías, la transparencia, la moralidad -esta última analizada desde la perspectiva del conflicto de intereses y de las causales de impedimento-. También se señala la necesidad de reforzar la seguridad jurídica mediante la codificación de temas dispersos, la simplificación y racionalización de procedimientos administrativos, lo que incluye avances tecnológicos que deben respetar la neutralidad tecnológica y el principio de igualdad, para lo cual hay que reconocer la diversidad regional y ciudadana del país.

El procedimiento administrativo aparece como la garantía para la protección de los derechos de las personas y de eficacia en la realización de los mismos. Por esta razón, el procedimiento incluye principios nuevos tales como el debido proceso, la buena fe, la moralidad, la participación de los ciudadanos, estableciendo, por ejemplo, que la omisión de la consulta previa es una causal de nulidad. Además, se incluyen reglas especiales para dirimir los conflictos de competencia administrativa y evitar la dilación en la respuesta que debe dársele al ciudadano.

Contar con procedimientos más ágiles y garantistas permite enviar un mensaje claro a los administradores públicos, los cuales deben entender que son los primeros protectores de los derechos fundamentales y que el ciudadano debe acceder a la justicia contenciosa sólo en casos excepcionales. El nuevo procedimiento administrativo procura 
responder también al esquema de un Estado constitucional, que pretende resolver los conflictos entre administración y ciudadanos en sede administrativa, reconociendo a estos su dignidad y la garantía de sus derechos fundamentales.

Para reforzar un nuevo esquema propio del constitucionalismo moderno, en el acápite dedicado a la consagración de los nuevos principios administrativos se observa la intención modernizadora de adecuar el derecho administrativo al Estado social y de derecho, con grandes implicaciones en sus categorías clásicas, tales como la conservación de la defensa objetiva de la legalidad, pero con énfasis en la eficacia de los derechos fundamentales, lo que permite entender un comienzo de transición del Estado de derecho al Estado social y de derecho.

Es así como los nuevos procedimientos incluyen, además de los principios clásicos del derecho administrativo, como la celeridad -apoyada esta vez en la tecnología para la información-, la eficacia, la economía, la imparcialidad, otros diez nuevos principios de raigambre constitucional que se encuentran, además, en todas las legislaciones de derecho comparado de América Latina, como son: debido proceso, igualdad, buena fe, moralidad, participación, responsabilidad y corresponsabilidad, transparencia, coordinación, descentralización y autonomía regional,los cuales se convierten a su vez en criterios de interpretación para resolver las cuestiones planteadas en sede administrativa, con el fin de lograr la eficacia y protección de los derechos. En la parte del procedimiento contencioso se debe garantizar el acceso efectivo a la justicia, la eficacia y la prontitud de las decisiones judiciales, para la efectiva tutela de los derechos.

Dicho de otro modo, los nuevos principios deben garantizar la efectividad de los derechos fundamentales por parte de la administración y al mismo tiempo la legalidad en los procedimientos.
En cuanto al principio del debido proceso, este sustituye la contradicción e incluye en el procedimiento administrativo la aplicación de máximas jurídicas tales como "Nula poena sine legem", la no "reformatio in peius", el "non bis in idem". El principio de la igualdad complementa la imparcialidad y exige que se proteja la desigualdad real. El principio de la buena fe deriva del artículo 83 de la Constitución, incluye el concepto de confianza legítima. El principio de la moralidad exige la rectitud, la lealtad y la honestidad en las decisiones, bajo el concepto de probidad. El principio de la participación exige que los ciudadanos opinen en el diseño, implementación y evaluación de las políticas públicas. El principio de la responsabilidad exige que el Estado responda por los daños que el ciudadano no está en la obligación de soportar. El principio de la transparencia sustituye al de la publicidad. El principio de la coordinación recoge los principios de eficacia, privilegiando lo sustancial.

Se ordena, además, aplicar el principio de proporcionalidad en el momento de imponer sanciones administrativas. Así mismo, en el procedimiento administrativo se estableció el principio de efectividad de las decisiones con la facultad de imponer sanciones a las personas naturales o jurídicas que sean renuentes a facilitar la información durante las investigaciones administrativas que se adelanten, o a quienes obstaculicen o impidan que aquella se allegue.

Específicamente, los principios de buena fe, moralidad, imparcialidad, coordinación, responsabilidad y transparencia ayudan a desarrollar el concepto de gobernabilidad, tan necesario en cualquier democracia.

Así mismo, la efectividad de las actuaciones se garantiza con la publicidad y con los deberes de atención al público. Es así como en el nuevo código se establece de manera expresa la obligación de la atención al público con un horario mínimo de $\mathbf{4 0}$ horas; se reitera la obligación de establecer turnos 
en orden de llegada; el trato digno; la utilización de medios electrónicos para el trámite de quejas y notificaciones, y la posibilidad de crear dependencias especializadas para la atención de quejas y reclamos y para la realización de las audiencias en sede administrativa.

\section{b. Mayor alcance al derecho de petición}

El derecho de petición se desarrolló en el nuevo código de una manera amplia, mejorando su alcance en favor del ciudadano. En las condiciones de forma, se estableció que ya no es necesario indicar que se trata de un "derecho de petición", sino que, por el contrario, cualquier solicitud ciudadana, verbal o escrita, sin importar las formalidades, debe entenderse como ejercicio del derecho de petición. Además, se reitera la obligación de los personeros de colaborar en su elaboración para los ciudadanos que lo soliciten.

Con el fin de incorporar la línea jurisprudencial de la Corte Constitucional respecto del contenido de las respuestas al derecho de petición, se indica que estas deberán ser motivadas, aplicando, además de las normas, la jurisprudencia unificada de la Corte Constitucional y del Consejo de Estado, en especial los artículos 102 y 269 que disponen la extensión de la jurisprudencia en materia administrativa, lo cual tendrá como efecto colateral la descongestión judicial al evitar miles de fallos en el mismo sentido.

Así mismo, se les recordó a los administradores públicos la obligación de garantizar el acceso a los documentos públicos y se incorporó de manera expresa la exigencia de respetar el debido proceso en todas las actuaciones administrativas, antes y después de la decisión, pudiendo los administrados participar en las decisiones que los afectan, solicitar y hacer valer pruebas cuando lo consideren necesario. Para efectos de garantizar el derecho al acceso a los documentos públicos, en caso de duda, la administración podrá solicitar concepto al Consejo de Estado sobre documentos que deben considerarse reservados.

De otra parte, se creó la figura de la atención prioritaria del derecho de petición, también Ilamada "tutela administrativa", la cual incluye la posibilidad de tomar medidas de emergencia o de urgencia sin necesidad de acudir a la tutela judicial- cuando se trata de un derecho fundamental amenazado o conculcado.

Igualmente, se amplió el alcance del derecho de petición al autorizar su ejercicio ante organizaciones e instituciones privadas, con lo cual se materializa la eficacia de este derecho de manera horizontal.

Para la atención de este derecho, las autoridades administrativas podrán crear grupos especializados encargados de elaborar proyectos de respuesta a los derechos de petición, y de decisión a los recursos de reposición y apelación. Se retomó la facultad otorgada por el legislador en la Ley 1265 del 2010, en el sentido de autorizar la recepción de peticiones por medio electrónico, así como las notificaciones por el mismo.

En lo que respecta al nuevo procedimiento administrativo, con el fin de garantizar el debido proceso, se facultó al ciudadano para pedir pruebas y exigir que se practiquen en su presencia. De otra parte, en aplicación del principio de la coordinación, las entidades no podrán imponer al ciudadano la carga de la prueba cuando los documentos reposen en otra institución del Estado. Por el contrario, deberán realizar las solicitudes interadministrativas que se requieran.

Para hacer efectivo el principio de la participación, se estableció como causal expresa de nulidad la omisión de la consulta previa cuando esta sea obligatoria. Por ejemplo, en los trámites para concesiones mineras, esta consulta a las comunidades étnicas es obligatoria. 
Otra de las innovaciones del procedimiento administrativo que intenta dar mayor alcance al derecho de defensa del ciudadano consiste en la ampliación del término a diez días para interponer los recursos de reposición y apelación en la vía gubernativa, pudiendo el ciudadano utilizar los medios electrónicos. Se reitera la admisión de la figura de la agencia oficiosa.

En cuanto a la revocatoria de los actos administrativos, se establecieron nuevas garantías. Es así como se prohíbe la revocatoria directa cuando el acto administrativo afecta derechos subjetivos; $y$ en todos los casos, para poder tramitarla en sede administrativa se requiere del consentimiento del tercero. Es decir, no se puede revocar el acto sin su consentimiento, por lo que si la administración se equivocó debe demandar ante el juez mediante acción de lesividad, solicitando la suspensión provisional del acto. Sin embargo, en este punto en especial, Enrique Gil Botero, Consejero de Estado de la Sección Tercera y miembro de la comisión redactora, manifestó, en el encuentro al que se hizo alusión en el inicio de este escrito, que él nunca estuvo de acuerdo con la incorporación de esta disposición, pues considera que la misma plasma un retroceso en materia de seguridad jurídica, ya que atenta contra los principios de la buena fe, confianza legítima e interés general. No es admisible que un acto que ostenta vicios de ilegalidad tenga efectos jurídicos hasta cuando sea anulado por un juez. Esta situación contraría principios constitucionales y afecta la eficacia en la consecución del interés general.

Otro avance importante, con respecto a la impugnación de actos administrativos, consiste en hacer compatibles y no excluyentes la vía gubernativa y la solicitud de revocatoria directa, en el caso de que los actos no estén conformes con el interés público o social, o atenten contra este. Eso no era posible en el código anterior, de acuerdo con el cual si el ciudadano optaba por solicitar la revocatoria cerraba la vía al contencioso. Quedó vigente la prohibición de solicitar revocatoria directa cuando el ciudadano haya interpuesto recursos contra un acto que se considera manifiestamente opuesto a la Constitución Política o a la ley, o cuando haya operado la caducidad. En estas dos situaciones, la solicitud de revocatoria directa no es procedente.

Por último, en cuanto al régimen sancionatorio en sede administrativa, el código estableció un procedimiento administrativo sancionatorio general, pero a su vez residual, el cual entraría a reemplazar los procedimientos actuales que hayan sido expedidos por acto administrativo, estableciéndose la figura de la derogatoria tácita. Sólo subsistirían los procedimientos sancionatorios especiales consagrados mediante ley, por ejemplo, en materia tributaria. Se indicó además que en estos procedimientos especiales se deberán aplicar las normas generales que llenen los vacíos existentes y que sean compatibles. Así mismo, se reitera y unifica la caducidad de tres (3) años para imponer cualquier tipo de sanción administrativa.

\section{c. La aplicación de la jurisprudencia unificada}

La aplicación de la jurisprudencia, esto es del contenido de las decisiones judiciales a casos similares, es una herramienta jurídica que le permite al ciudadano un trato igualitario por parte de los jueces y los administradores públicos. En otros términos, con la aplicación del precedente judicial, fruto de una jurisprudencia unificada -razón de ser, entre otras, de los organismos de cierre de las distintas jurisdicciones-, se garantiza de mejor forma el principio de igualdad en el acceso a la justicia de parte de los ciudadanos.

El nuevo código estableció la extensión de la jurisprudencia no sólo para los jueces sino también para las decisiones en sede administrativa, lo cual trae como efecto colateral el aseguramiento de la actuación de la administración pública y, por ende, la tutela efectiva de los derechos. Además, genera un mayor compromiso de los operadores 
jurídicos con respecto a la construcción colectiva de la jurisprudencia por parte de las altas cortes.

Diego López Medina (2008: 48 y ss.), en su obra El derecho de los jueces, explica cómo los precedentes judiciales en los países anglosajones generan mayor coherencia jurídica interna, seguridad jurídica e igualdad en la aplicación de la ratio decidendi. La extensión de la jurisprudencia en sede administrativa genera además progreso jurídico, facilita el acceso a la administración pública, disminuye los costos de transacción, evita la congestión judicial, hace efectivo el derecho a la igualdad, mejora el actuar de la función pública y de la justicia, debido a que hace predecibles los fallos, la igualdad y la transparencia, en todas las actuaciones administrativas y judiciales, con lo cual desaparece, en gran medida, la sospecha de prevaricato y arbitrariedad de los jueces.

Tal y como quedó establecida la aplicación de la jurisprudencia en este nuevo código, las autoridades administrativas no podrán apartarse del precedente judicial, so pena de incurrir en el delito de desacato a orden judicial. El juez, por el contrario, sí podrá apartarse, pero argumentando y explicando por qué las circunstancias diversas hacen que el caso no sea homogéneo con los precedentes, con lo cual se garantiza la independencia judicial.

Las sentencias de unificación serán aquellas que se surtan en los casos que escoja el Consejo de Estado por su trascendencia social y su repercusión jurídica, o también en aquellos que por solicitud de parte se estudien en sala plena, tal y como lo establece el artículo 102. Así mismo, un tercer mecanismo en procura del trato igualitario para todas las personas consiste en que el ciudadano podrá pedir a la administración que se apliquen las sentencias unificadas. Si esta se niega, podrá acudirse al Consejo de Estado en recurso de extensión, según lo establecido en el artículo 269, para que este imponga la aplicación de la sentencia unificada a la administración.

\section{d. Los principales cambios en el procedimiento contencioso administrativo}

En el procedimiento contencioso administrativo también se realizaron cambios significativos, tales como la reorganización de las competencias y los medios de control, la inclusión de un procedimiento mixto y el avance hacia la oralidad, las medidas cautelares, los medios probatorios, el establecimiento del recurso extraordinario de extensión de la jurisprudencia, la ampliación de las competencias en materia laboral y contractual, el establecimiento de dos causales nuevas para la nulidad electoral,entre otros aspectos.

\section{1) La competencia de la jurisdicción y los medios de control}

En el nuevo código la organización de la jurisdicción contenciosa se efectuó bajo un esquema mixto. Se utilizó fundamentalmente el criterio material en la distribución de competencias, pero también acogió, en algunos casos precisos, el criterio orgánico y funcional teniendo en cuenta la naturaleza del asunto, para lo cual se señala una lista taxativa de asuntos con independencia de que las partes sean personas públicas o privadas, por ejemplo, en materia de contratación estatal o de responsabilidad extracontractual.

El nuevo estatuto cobija a todas las autoridades públicas en función administrativa. El anterior sólo hablaba de autoridades administrativas. Ahora se habla de medios de control y de pretensiones, ya no de acciones. Esta nueva perspectiva permite la acumulación de pretensiones y prevé el cambio de competencias, garantizando así un mejor acceso a la justicia.

Como requisitos de procedibilidad de las pretensiones, se mantiene la exigencia del agotamiento de la vía gubernativa y de la conciliación prejudicial. Lo anterior, por cuanto se considera que la administración debe ser la primera en dar eficacia a los derechos de los administrados. Además, las 
entidades públicas podrán conciliar entre sí sin necesidad de ser demandadas.

El Consejo de Estado mantiene su carácter de juez de instancia y no de juez extraordinario de revisión. Esta misión se consagra acogiendo la Sentencia de la Corte Constitucional C-520 de 2009. Sin embargo, se establece el recurso extraordinario de extensión y unificación de la jurisprudencia para aquellos fallos que se profieran desconociendo las sentencias de unificación del Consejo de Estado.

En cuanto a los conceptos que expide la sala de Consulta del Consejo de Estado, el término de reserva se disminuye. Con el nuevo estatuto esta solamente será de seis meses, en vez de los cuatro años anteriores. Además, se establece que la reserva puede tener un término menor si la entidad consultante permite que se haga público el concepto.

\section{2) El procedimiento mixto y facultativo y los nuevos recursos}

El procedimiento general de lo contencioso continúa siendo residual, lo que quiere decir que se siguen respetando los procedimientos especiales. Además, en su desarrollo se admite un sistema mixto que introduce la oralidad y a la vez que permite los procedimientos escriturales al estilo alemán. Sin embargo, el juez no puede escoger un solo sistema -oral o escrito- desde el principio del proceso, como sí ocurre en Alemania.

El nuevo procedimiento propende por la virtualidad al permitir, por ejemplo, la grabación de las audiencias.

En el desarrollo del proceso se establecen tres audiencias: la inicial o de determinación del litigio, la de pruebas y la de alegaciones y juzgamiento. Esta última es facultativa y el juez puede allí dictar el fallo o, por el contrario, indicar únicamente el sentido del mismo, con la facultad de tomarse los treinta días siguientes para redactarlo. En los casos en los que se trate de cuestiones de puro derecho, se puede fallar en la primera audiencia. En los casos similares, también llamados "casos testigo", se puede prescindir de todas las audiencias.

Los jueces deben realizar actuaciones de saneamiento en cada una de las etapas o audiencias del proceso, es decir actuar además como jueces de control. Las posibles nulidades que se presenten deben plantearse por las partes en las audiencias, so pena de considerarse saneadas, a menos que se trate de nulidades sobrevinientes. Además, se pueden presentar excepciones mixtas en las audiencias. Por ejemplo, si en el momento de admitir la demanda se omitió la verificación de alguno de los presupuestos procesales, el juez puede decidir en la misma audiencia y dar por terminado el proceso.

En las tres etapas del proceso existe siempre la posibilidad de conciliar. El juez debe propiciar la aproximación entre las partes sin que ello constituya prejuzgamiento. La regla en materia probatoria es aquella de los procesos dispositivos, en el sentido de que son las partes las que tienen la carga de la prueba. Por lo tanto, son estas las que las deben aportar. Se admiten excepcionalmente las pruebas de oficio. Sin embargo, a nivel de la doctrina, como se sabe, se ha desechado esta posibilidad porque puede conducir a desequilibrar los derechos de las partes. Así mismo, en todas las audiencias se exige brevedad. Las intervenciones no pueden ser mayores a diez minutos. Las audiencias pueden celebrarse aun sin la presencia de los apoderados, si estos se excusan previamente con causa justa.

Se amplían los plazos para la contestación de demanda a treinta días, para que el demandado pueda preparar mejor su defensa. Además, se autoriza a este para pedir ampliación del plazo cuando pretenda allegar prueba pericial hasta por un término de diez días más. 
Para efectos de notificaciones se acogen los medios electrónicos. Se suprimió la fijación en lista y se autoriza la notificación en estrados y por medio electrónico.

El término para interponer el recurso de apelación contra sentencias se amplió a diez días, lo mismo el previsto para reformar o adicionar la demanda, pudiéndose efectuar a través de medios electrónicos.

El auto que rechaza la demanda o su contestación ya no puede ser apelable, situación que podría vulnerar el derecho de defensa, tema que deberá analizar la Corte Constitucional en su momento.

Así mismo, solamente es apelable y exclusivamente por parte del Ministerio Público el auto que aprueba la conciliación judicial, con lo cual desapareció la apelación contra el auto que imprueba una conciliación, circunstancia esta que vulneraría el derecho de defensa. La reforma también restringió la apelación para terceros, que tan solo podrán interponer dicho recurso cuando se niegue su intervención en el proceso. Igualmente, se suprimió la apelación contra el auto que niega el mandamiento de pago, disposición preocupante que puede amparar la arbitrariedad judicial.

El recurso de apelación contra la sentencia deberá presentarse ante el a quo por escrito y luego sustentarse oralmente en la audiencia de conciliación, la cual deberá realizarse por el juez antes de ser remitido el asunto a la segunda instancia, reiterándose lo establecido ya en la Ley 1395 de 2010. Si el recurrente no acude a esta audiencia se declara desierto el recurso. Esta audiencia no tiene mucha relevancia en la práctica debido a que casi nunca existe ánimo conciliatorio de las partes, por lo que algunos doctrinantes consideran que la sanción por la inasistencia a la audiencia es arbitraria, amén de que si el recurrente ya sustentó por escrito el recurso, no es lógico que se le declare desierto. Además, esta última audiencia generará mayor congestión, efecto contrario al pretendido por la reforma.

En cuanto al recurso extraordinario de unificación de la jurisprudencia, este se encuentra plasmado en los artículos 256 a 268, en concordancia con el artículo 102 que establece la forma de aplicación de la extensión de la jurisprudencia, y de los 272 a 274 donde se lee cómo opera el mecanismo eventual de revisión. Así mismo, en el artículo 303, numerales $6^{\circ}$ y $7^{\circ}$, se establecieron las atribuciones del Ministerio Público para pedir la extensión. Es importante anotar que este recurso se tramita en todos los casos en el efecto devolutivo.

\section{3) Las medidas cautelares y los poderes del juez}

El nuevo código fortalece los poderes del juez a través de las nuevas medidas cautelares en todos los procesos declarativos que se adelanten ante esta jurisdicción. Con las nuevas facultades el juez, en el momento de imponer dichas medidas, no sólo puede suspender el acto demandado sino que, además, puede ordenar, por ejemplo, el reintegro de un funcionario, la suspensión de un procedimiento, de un concurso o de una licitación. Sin embargo, a la hora de tomar la medida, el juez debe indicar las pautas para reanudar el procedimiento suspendido.

Este puede también ordenar la realización de obras o demoliciones, expedir órdenes de hacer o no hacer para evitar el desconocimiento sistemático del derecho por parte de la administración y/o para asegurar la efectividad de la decisión judicial. Las mismas se pueden solicitar en cualquier estado del proceso, debiendo el demandante hacer referencia a la norma o normas constitucionales que se reporten vulneradas. El juez sólo podrá estudiar la norma o normas que se aleguen en el escrito de medida cautelar. 
El auto que decreta la medida es susceptible de apelación o de súplica cuando la expide un magistrado de tribunal. Sin embargo, el código no es claro con respecto a si la medida la decreta el magistrado ponente o la sala respectiva, dado que surgen contradicciones entre lo establecido en el artículo 125 y lo dispuesto en los artículos 123 y 243.

\section{4) Los medios probatorios}

En materia de pruebas, las copias simples adquieren valor probatorio, dando alcance al artículo 254 del nuevo código, que exige que en los procesos prevalezca lo sustancial sobre lo procesal. Los dictámenes de peritos pueden ser allegados por las partes. Además, el demandando puede pedir ampliación del plazo para contestación de demanda con el fin de allegar su dictamen pericial.

Según el artículo 214 del nuevo código, el juez puede realizar la exclusión de cualquier prueba cuando considere que se practicó con violación del debido proceso. Este artículo recoge lo establecido en el artículo 29 de la Constitución Política al implantar lo allí dispuesto de la nulidad de pleno derecho.

\section{5) Los medios de control $y$ las pretensiones}

En lo relacionado con las pretensiones, se creó la acción única con pretensión múltiple, lo que admite la acumulación de las mismas. Ya no se habla, por tanto, de acciones sino de pretensiones y medios de control.

Específicamente para el control de nulidad y restablecimiento del derecho en el caso de pretensiones laborales, se amplió la competencia para los conflictos relacionados con la seguridad social. Además, se autoriza a la entidad que resulte condenada a cambiar el reintegro del funcionario por una indemnización económica, cuando no pueda ubicarlo dentro de la planta. En materia de pretensiones contractuales se incluyen los contratos con cláusulas exorbitantes, como podría ser el caso de las empresas de servicios públicos domiciliarios de carácter privado.

Para las pretensiones relacionadas con el control de nulidad por inconstitucionalidad, el juez podrá pronunciarse sobre normas no demandadas que guarden unidad jurídica con los artículos demandados, según lo establece el artículo 135.

Respecto de la pretensión de nulidad establecida en el artículo 137, el nuevo código acoge la teoría de los móviles para aceptar que el medio de control se puede interponer contra actos de contenido particular: I) cuando no se busque el restablecimiento automático del derecho; II) para recuperar bienes de uso público; III) cuando tenga efectos nocivos en el orden público, político, social o ecológico, y IV) cuando la ley lo consagre expresamente.

Respecto del medio de control de la nulidad electoral, en el código actual se prohíbe que las partes discutan este tema por la vía de acción de tutela o de la acción popular. Para dar más garantías a este derecho constitucional, se amplía el término de caducidad de la acción a treinta días hábiles. La nulidad electoral la pueden interponer también las personas jurídicas, por ejemplo, los partidos políticos a quienes por jurisprudencia se les otorgó la propiedad de las curules. En el nuevo código se incluyen dos causales nuevas: la trashumancia y la doble militancia política.

En cuanto al medio de control para la reparación directa del artículo 140, se acaba con la figura de la solidaridad para la reparación del daño. Ahora se habla de proporcionalidad para responder tanto los particulares como las entidades públicas involucradas, lo que generará mayor equilibrio en la protección de los derechos. 
En el medio de control denominado protección de derechos e intereses colectivos del artículo 144, se exige una reclamación previa a la entidad o al particular renuente. Además, se le prohíbe al juez anular o suspender los contratos en ejecución con base en esta acción popular. Sin embargo, el juez sí puede tomar las medidas necesarias para evitar la amenaza del derecho colectivo. De otra parte, en el medio de control de reparación de los perjuicios causados a un grupo, se admite expresamente que se puede utilizar para dirimir temas laborales. En este punto se observa cómo el código entra a regular una norma especial -la Ley 472 de 1998-, situación que podría no soportar una revisión constitucional.

Además, el código crea un nuevo medio de control denominado "control por vía de excepción", establecido en el artículo 148, mediante el cual se producen fallos con eficacia inter-partes cuando los actos administrativos vulneran la Constitución o la ley, decisión que sólo produce efectos en relación con el proceso dentro del cual se adopte. Se reitera que esta decisión puede llegar a tener efectos ex nunc o ex tunc, según lo disponga la sala respectiva, tal y como ocurre hoy también con los fallos de inexequibilidad proferidos por la Corte Constitucional.

\section{CUESTIONAMIENTOS A ALGUNOS ASPECTOS DE LA REFORMA DEL CÓDIGO DE PROCEDIMIENTO ADMINISTRATIVO Y DE LO CONTENCIOSO ADMINISTRATIVO}

En primer lugar, se anota que este código pretende convertirse en uno de los pilares del diseño de la política pública de acceso efectivo a la administración pública y a la justicia contenciosa.

Sin embargo, en el texto se dejaron por fuera aspectos fundamentales que inciden en el buen diseño y en la correcta implementación de dicha política, la ausencia de lineamientos para la correcta aplicación y revisión de las sentencias unificadas, la conservación del silencio administrativo, los riesgos del activismo judicial, la conservación de una ideología individualista y de una justicia rogada.

De otra parte, se afirma que la reforma al código debió coordinar, de manera simultánea, los desarrollos reglamentarios -mediante acuerdos del Consejo Superior de la Judicatura-, requeridos para mejorar la implementación de la Ley 270 de 1996 "Estatutaria de la administración de justicia" en lo relativo a la gestión administrativa y del talento humano de los jueces y magistrados del contencioso administrativo, con el fin de corregir las inequidades en la actual planta de personal de los juzgados unipersonales y las deficiencias en la elaboración de los indicadores de evaluación de gestión de los funcionarios y empelados de esta jurisdicción.

Al observar la forma como se vienen transformando los Estados modernos en Europa en torno al compromiso para lograr el diseño e implementación de políticas públicas integrales, cuya primera concreción se da en el sistema jurídico vigente a través de la unificación de normas en los códigos, podemos afirmar que en Colombia la reforma al Código de Procedimiento Administrativo y de lo Contencioso Administrativo no alcanzó a plasmar todos los aspectos que se requieren para efectivizar una política pública de acceso a la administración pública y a la justicia.

Para entender cuáles son las falencias de la reforma, se traen a colación los logros obtenidos en Francia en materia de política pública para la educación, cuyo pilar fundamental es el Código de Educación expedido en el año 2000 (Code d'éducation, 2000) que logró compilar todas las normas legislativas y decretos reglamentarios dispersos, estableciendo, además de los grandes principios, la organización y la administración del sistema, incluyendo temas fundamentales como la financiación del sistema educativo, la vida escolar, la carrera y criterios de evaluación de los docentes, 
las garantías, derechos y deberes de todos los actores del sistema.

\section{a. Ausencia de lineamientos para la aplicación y revisión de las sentencias unificadas}

La reforma adoptó el mecanismo de la extensión de la jurisprudencia en sede administrativa y judicial, sin embargo no previó los lineamientos para su aplicación respecto de la determinación de la ratio decidendi, o la posibilidad de realizar variaciones o modificaciones a dichas sentencias, en la medida en que las condiciones sociales 0 políticas lo exijan.

Se recuerda que una originalidad de nuestro código consiste en que este siempre ha reunido ambos procedimientos, el administrativo y el contencioso, situación muy diferente a la que existe en Europa. Sin embargo, esto no es óbice para desconocer que el derecho colombiano administrativo es de origen francés, que nace de la escuela del derecho continental y no del anglosajón. De allí la existencia de un estatuto jurídico especial para el contencioso administrativo, de un régimen de servidores públicos independiente y de unos jueces especializados en las controversias administrativas, cuyo máximo tribunal es el Consejo de Estado, muy similar al sistema francés, tal y como lo describe Ferdinand Mélin. Soucramanien (2009).

Sin embargo, tampoco se puede desconocer que en los últimos años se vienen incorporando instituciones jurídicas del derecho administrativo alemán, como se desprende de la simple lectura de la obra del "padre" de ese derecho en Alemania, el profesor Otto Mayer (1982: tomo IV, pp. 24 y ss.). En esta explica cómo dicho sistema normativo fue altamente influenciado por la escuela pandectística, lo que permitió emprender un exitoso camino doctrinal de construcción del derecho público desde el reconocimiento del poder público, con una corriente científica que concibe la función administrativa como el "hacer" del Estado, titular de amplias atribuciones jurídicas y nunca reducido a la simple ejecución de la ley, sin descuidar las realidades que estructuran el ordenamiento nacional. Por ello, los mecanismos alternativos de solución de conflictos, tales como la conciliación, operan en este país sin mayores dificultades. En Colombia se incluyó la conciliación dentro del proceso contencioso desde 1998. Así mismo, se han venido incorporando algunos principios y prácticas del sistema anglosajón, como por ejemplo la Ley 446 de 1998 o la 1395 de 2010, que disponen y convierten las audiencias de conciliación prejudicial en audiencias obligatorias, volviéndolas un requisito de procedibilidad y permitiendo a los particulares, como en el caso de los tribunales de arbitramento, la solución de conflictos contractuales y de reparación directa.

El nuevo código va más allá. Es así como vuelve obligatoria la aplicación del precedente judicial en sede administrativa y exige la unificación de la jurisprudencia por parte del Consejo de Estado en temas de trascendencia nacional, dándole al precedente judicial el carácter de fuente del derecho, tal y como ocurre en el derecho anglosajón. Con esta nueva reforma, la jurisprudencia deja de ser un criterio auxiliar o indirecto, para convertirse en fuente del derecho administrativo.

Sin embargo, existen muchas reservas doctrinales respecto de este "avance" del derecho continental colombiano hacia el "derecho anglosajón". Varias de ellas las explicó la Contralora General de la República, doctora Sandra Morelli Rico, y por el Auditor General de la República, Iván Darío Gómez, en el seminario internacional que organizó el Consejo de Estado el pasado 3 de febrero de 2011, con ocasión de la reforma. En sus intervenciones hicieron alusión a los fallos C-038 de 1995, m. p. Eduardo Cifuentes, y C-083 de 1995 de la Corte Constitucional, m.p. Carlos Gaviria Díaz. En este último fallo, la Corte estudió la constitucionalidad del artículo 48 de la Ley 153 de 1887, a la luz del artículo 150-1 de la Carta, para concluir que 
resulta inconstitucional pretender que sea sólo el Congreso el que tenga el derecho a interpretar por vía de autoridad, por cuanto la labor de la Corte Constitucional se encamina a guardar la supremacía y la integridad de la Carta, lo que hace que ella sea la responsable de interpretar con autoridad y de definir los alcances de los preceptos contenidos en la ley fundamental, especialmente en materia de revisión de tutelas. Así mismo, en el Fallo C-038 de 1995 se dijo que la aplicación del precedente judicial de la Corte Constitucional es obligatorio para los jueces, quienes pueden apartarse pero esgrimiendo sus argumentos. Además, se indicó que este precedente judicial se encuentra en la ratio decidendi de los fallos que se vienen reiterando sobre el alcance de un mismo derecho fundamental.

En Colombia venía siendo obligatoria la aplicación del precedente judicial pero sólo en materia constitucional, de conformidad con la Sentencia C-038 de la Corte Constitucional, la llamada "cosa juzgada material". A los expositores, en opinión de Sandra Morelli Rico e Iván Darío Gómez Lee, les resulta muy arriesgado extender esta regla al Contencioso, pues podría llevar a un anquilosamiento del derecho administrativo y al desconocimiento sistemático de algunos derechos en aras de proteger los intereses generales del Estado. Además, observan los mismos críticos cómo el legislador no previó los lineamientos para la aplicación de las sentencias unificadas; no se determinaron las reglas para extraer la ratio decidendi de los fallos y para aplicarlos o no a casos análogos.Tampoco se previó la posibilidad de realizar variaciones o modificaciones a las jurisprudencias que se constituyan en precedentes, en la medida en que las condiciones sociales 0 políticas varíen y así lo exijan.

\section{b. Conservación de la obsoleta figura del silencio administrativo e inexistencia de la obligación de realizar el derecho desde el punto de vista material y técnico}

La reforma al código decidió conservar la figura del silencio administrativo positivo o negativo, permitiendo la revocatoria directa del positivo, lo que a juicio del conocido administrativista español Luciano Parejo Alfonso, en su intervención realizada en el seminario antes citado de febrero de 2010, iría en contra de la seguridad jurídica que hoy se le exige en los Estados democráticos. Anota este que en Europa tal figura está llamada a desaparecer debido precisamente a que no garantiza los derechos del ciudadano ni del público, por lo cual en la mayoría de legislaciones se prefiere exigir, en todos los casos, una respuesta oportuna de la administración, sancionando ejemplarmente al funcionario que no se pronuncie. En todo caso, si el funcionario contesta favorablemente pero de manera extemporánea, en cualquier tiempo, se admite el desistimiento, lo cual no ocurre en Colombia, pues el nuevo código le niega al juez la posibilidad de admitir el desistimiento de la pretensión después de admitida la demanda, aún cuando exista respuesta favorable de la administración. Parejo considera que esta norma, además, va en contravía de la descongestión judicial.

En segundo lugar, el nuevo código acoge la tesis del sistema alemán de resolver derechos subjetivos sobre los que recaen las pretensiones y no las acciones. Sin embargo,el derecho alemán continúa siendo aún más avanzado, pues ese país no sólo exige la realización del derecho desde el punto de vista jurídico, sino también material y técnico, y el juez debe observar que la actuación de la administración se haya efectuado con resultados exitosos. La opción colombiana regula únicamente el procedimiento administrativo, termina velando únicamente por sus efectos jurídicos, más no se ocupa de verificar los resultados materiales o técnicos de la decisión.

En tercer lugar, a diferencia del derecho alemán o francés, en el nuevo código se observa que el legislador le dio una escasa atención a la facultad discrecional de los administradores públicos, mientras que en aquellos países, y en general 
en Europa, este tema es de crucial importancia, razón por la cual en sus códigos de procedimiento administrativo se regula taxativamente dicha facultad, a fin de evitar que esta quede al arbitrio interpretativo del funcionario de turno.

En cuarto lugar, el profesor Parejo, refiriéndose al nuevo código, indicó que existe un problema de coherencia entre los objetivos de este, por cuanto en el primer libro se señala que pretende la efectividad de los derechos y al mismo tiempo la conservación del orden jurídico. Sin embargo, históricamente está demostrado que estos dos ámbitos no son correlativos. Así mismo, observó que el procedimiento administrativo comprende una perspectiva funcional -actuación de la administración la cual es amplia e incluye a los particulares-, mientras que el procedimiento contencioso habla de actos, hechos, omisiones, lo que hace muy extenso el ámbito de su aplicación, pero sólo se habla de entidades públicas, es decir, no se incluye a los particulares. La jurisprudencia deberá dilucidar este problema de coherencia.

\section{c. Riesgo de activismo judicial con base en las nuevas facultades del juez para imponer medidas cautelares}

En cuanto a la facultad del juez de imponer medidas cautelares, tales como ordenar la realización de obras o demoliciones, el profesor Parejo pregunta: ¿hasta dónde puede ir la iniciativa del juez?

Estas nuevas facultades podrían conducir al juez a un activismo judicial y a una cogestión de la administración pública, muy dañina para un Estado con clara separación de poderes.

Sin embargo, el mismo profesor no desconoce que las medidas cautelares serían defensables en muchos casos en los cuales la eficacia del fallo depende de ellas.

\section{d. Mantenimiento de un esquema de justicia rogada y del procedimiento dispositivo para la práctica de pruebas que atenta contra la exigencia de búsqueda de la justicia material}

El nuevo código mantuvo en esencia las exigencias de una justicia rogada para el contencioso administrativo, en especial en lo relativo al proceso dispositivo en la práctica de pruebas, con la posibilidad de decretarlas de oficio sólo en casos excepcionales. El anterior código administrativo consagraba, en el artículo 137-4, el principio de la justicia rogada, el cual se declaró exequible en Sentencia C-197 de 1999 de la Corte Constitucional.

En esta sentencia, la Corte Constitucional sostuvo que el juez contencioso administrativo debe realizar un análisis de legalidad de las normas, lo que implica una legalidad material y no meramente formal que involucra no solo el análisis de la ley, sino además de la Constitución. Consideró, por tanto, que el juez no puede limitarse al enjuiciamiento de las normas invocadas y el concepto de violación expuestos por el demandante, sino que debe realizar su propio examen de legalidad a la luz del sistema normativo vigente.

En el nuevo código se flexibiliza esta disposición, al permitirse el examen de la norma violada del nivel nacional a la luz de toda la normatividad, independientemente de la argumentación presentada por el demandante.Sin embargo, se considera que la reforma debió avanzar más y eliminar la justicia rogada para las acciones de reparación directa, permitiéndole al juez ser el director del proceso y sin que deba limitarse al análisis o a las pruebas que presente el demandante o el demandado, pues se trata de hechos, operaciones u omisiones que son en muchos casos de interés general, por ejemplo en el de las masacres o de los atentados terroristas. En aras de buscar la justicia material, se 
le debería permitir al juez examinar los hechos a la luz de los derechos fundamentales consagrados en la Constitución, buscando establecer la responsabilidad objetiva del Estado, según lo señalado en el artículo 90 de la Constitución Política, que prohíbe a las autoridades imponer al ciudadano cargas que este no está en el deber de soportar.

\section{e. Conservación de una ideología individualista en detrimento de los derechos colectivos}

Tal y como lo ha expresado Jaime Orlando Santofimio Gamboa,Consejero de Estado, en su intervención en el seminario ya citado de febrero de 2010, el código mantuvo una ideología esencialmente individualista y no avanzó hacia la apropiación de los derechos colectivos. Es así como el texto omite reglas o mecanismos de protección que se hubieran podido incorporar para la realización de los derechos colectivos y, por el contrario, limita el acceso a las acciones populares, exigiendo para su procedibilidadel agotamiento del trámite administrativo.

\section{CONCLUSIONES}

El nuevo Código de Procedimiento Administrativo pretende alcanzar una administración pública transparente en contacto más directo con el ciudadano y al servicio de la comunidad. Se espera, por tanto, que el Estado colombiano utilice más intensivamente, para el logro de los anteriores objetivos, la comunicación virtual para la transmisión de información veraz y oportuna que le permita al ciudadano conocer la marcha de la administración fiscalizante y obtener respuesta oportuna a sus demandas.

El éxito de la reforma depende de los recursos que se logren ejecutar para llevar a cabo los cambios anhelados y para generar proyectos de gestión del talento humano y de gestión administrativa, que permitan capacitar y motivar a los funcionarios de la administración y de la rama judicial para asumir la nueva cultura institucional, y realizar las adecuaciones logísticas y tecnológicas que se requieren.

Otro gran reto para los jueces de las altas cortes es el de lograr que la unificación de la jurisprudencia sea eficaz; esto es, acatada por las instancias inferiores de la Judicatura. Se requiere, por tanto, que exista un control efectivo de la actuación de la administración respecto de la aplicación de la extensión de la jurisprudencia. Para ello, se necesitará el apoyo permanente de los diferentes órganos de control, así como de la aplicación de un sistema sancionatorio severo y oportuno.

De otra parte, a nuestro juicio quedó pendiente en la reforma la necesaria unificación de todos los procedimientos especiales en un solo código.

Finalmente, un aspecto que, desde luego, no podía incluirse en la reforma pero que afecta el cumplimiento oportuno de las sentencias de tipo condenatorio, es el relativo a la búsqueda de una fórmula efectiva para el pago de estas. En Panamá, por ejemplo, es el Banco de la República el que realiza el pago de de las sentencias contra el Estado. En Colombia, se continúa en un círculo vicioso. Aunque se avanzó con la creación del Fondo de contingencias que gestiona el Ministerio de Hacienda, aquel aún no ha sido reglamentado y de todos modos la responsabilidad del pago sigue recayendo en la entidad condonada y no en dicho ministerio, lo cual genera en la práctica moras injustificadas en contra de los ciudadanos damnificados.

\section{REFERENCIAS}

Gil Botero, E. (2011, febrero 1, 2 y 3). Recursos, silencio administrativo y revocatoria directa. Bogotá: Biblioteca Luis Ángel Arango, Seminario Internacional del Contencioso.

Gómez Lee, I.D. (2011, febrero 1, 2 y 3). Los retos de la implementación del nuevo código. Bogotá: 
Biblioteca Luis Ángel Arango, Seminario Internacional del Contencioso.

López Medina, D. (2008). El gobierno de los jueces. Bogotá: Temis.

Mayer, O. (1982). Derecho administrativo alemán. Buenos Aires: Traducción de Editorial De Palma.

Morelli Rico, S. (2011, febrero 1, 2 y 3). La incidencia del nuevo código en el mejoramiento de la gestión pública. Bogotá: Biblioteca Luis Ángel Arango, Seminario Internacional del Contencioso.

Parejo Alfonso, L. (2011, febrero 1, 2 y 3). El nuevo código en la perspectiva comparada. Bogotá: Biblioteca Luis Ángel Arango, Seminario Internacional del Contencioso.

Santofimio Gamboa, J.O. (2011, febrero 1, 2 y 3). La incidencia del nuevo código en el fortalecimiento del ordenamiento jurídico. Bogotá: Biblioteca Luis Ángel Arango, Seminario Internacional del Contencioso.

Torres Corredor, H. (2011, febrero 1, 2 y 3). Informe anual del Consejo Superior de la Judicatura. Bogotá: Biblioteca Luis Ángel Arango, Seminario Internacional del Contencioso.

Yong Serrano, S. (2009). Introducción a la responsabilidad pública y privada. Bogotá: Editorial Universidad Santo Tomás.

\section{NORMATIVIDAD, CÓDIGOS, LEYES, ACUERDOS}

Código Contencioso Administrativo (2010). Decreto 01 de 1994. Legis.

Código de la educación (Code de l'éducation). (2010). Francia: Leger. Consultado en www.education.gov.fr, último acceso: febrero 5 de 2011.
Consejo Superior de la Judicatura. (2006). Acuerdo PSAA06-3409. Colombia.

Consejo Superior de la Judicatura. (2010). Acuerdo 7636. Colombia.

Constitución Política de Colombia. (2010). Legis.

Ley 1395. (2010). Descongestión judicial. Consultado en www.ramajudicial.gov.co, último acceso: febrero 11 de 2011.

Ley 1425. (2010). Eliminación del incentivo de las acciones populares. Consultado en www.ramajudicial.gov.co, último acceso: febrero 11 de 2011.

Ley 1437. (2011). Nuevo Código de Procedimiento Administrativo y de lo Contencioso Administrativo. Consultado en www.ramajudicial.gov.co, último acceso: febrero 11 de 2011.

\section{JURISPRUDENCIA}

Cifuentes, E. (1995). Sentencia C-038 de 1995. Corte Constitucional.

Córdoba Triviño, J. (2009). Sentencia C-520 de 2009. Corte Constitucional.

Gaviria, C. (1995). Sentencia C-083 de 1995. Corte Constitucional.

\section{REFERENCIAS COMPLEMENTARIAS}

Bozeman, B. (1998). Todas las organizaciones son públicas. México: Fondo de Cultura Económica, Colegio Nacional de Ciencias Políticas y Administración Pública.

Cossio Díaz, J.R. (1989). Estado social y derechos. Madrid: Centro de Estudios Constitucionales.

De Souza Santos, B. (1999). La globalización del derecho, los nuevos caminos de la regulación y la emancipación. Bogotá: ILSA. 
Doering, K. (1986). Estado social, estado de derecho y orden democrático. Madrid: Centro de Estudios Constitucionales.

Eamonn, K. (2009). La década decisiva. Tres escenarios para el futuro del mundo. Bogotá: Grupo Editorial Norma.
Garronera Morales, A. (1992). El Estado español como Estado social y democrático de derecho. Madrid: Editorial Tecnos.

Mélin-Soucramanien, F. y Pactet, P. (2009). Derecho constitucional francés (Droit constitutionnel). París: Dalloz-Sirey. 